\title{
PENGARUH KOMUNIKASI INTERPERSONAL DAN STRES KERJA TERHADAP KOMITMEN ORGANISASI PEGAWAI PUSDIKLAT BEA DAN CUKAI
}

\author{
THE EFFECT OF INTERPERSONAL COMMUNICATION AND \\ JOB STRESS ON ORGANIZATIONAL COMMITMENT ON EMPLOYEE AT \\ CUSTOMS AND EXCISE TRAINING CENTER
}

\author{
Rita Dwi Lindawati ${ }^{1}$
}

\begin{abstract}
The objective of the research is to know the effect of interpersonal communication and job stress on organizational commitment on employee. This research used quantitative approach. The research was conducted of Customs and Excise Training Center by using a survey method with path analysis applied in testing hypothesis. The number of 50 employee as sample was selected by using Slovin formula. The research conclude: (1) There is a direct positive effect of interpersonal communication on organizational commitment (2) There is a direct negative effect of work stress on commitment organization (3) There is a direct negative effect of interpersonal communication on organizational commitment.
\end{abstract}

Keywords: Interpersonal communication, job stress and organizational commitment.

\section{PENDAHULUAN}

Sesuai Peraturan Menteri Keuangan Nomor 184/PMK.01/2010 tentang Organisasi dan Tata Kerja Kementerian Keuangan, maka Pusdiklat Bea dan Cukai sebagai unit eselon II dibawah Badan Pendidikan dan Pelatihan Keuangan (BPPK) mempunyai tugas membina pendidikan, pelatihan dan penataran keuangan negara di bidang kepabeanan dan cukai berdasarkan kebijakan teknis yang ditetapkan oleh Kepala BPPK. Sekarang ini Pusdiklat Bea dan Cukai sedang terus berusaha untuk membenahi sumber daya manusianya untuk mengemban transformasi kelembagaan yang sedang dilakukan oleh BPPK.

Transformasi kelembagaan itu dirasa penting agar organisasi BPPK dapat berjalan semakin efektif. Kesuksesan transformasi kelembagaan bergantung pada kesiapan sumber daya manusia sebagai kuncinya. Berbagai langkah strategis telah ditempuh untuk mempersiapkan sumber daya manusia melalui penyamaan komitmen terhadap transformasi, kesiapan atas perubahan uraian jabatan, serta pemahaman yang komprehensif atas proses bisnis. Setiap insan BPPK wajib memberikan kontribusi untuk mewujudkan BPPK yang lebih baik.

Seperti yang telah diuraikan pada paragraf sebelumnya, komitmen organisasi pegawai menjadi salah satu langkah strategis untuk mewujudkan transformasi kelembagaan yang sedang dilaksanakan oleh BPPK pada umumnya dan Pusdiklat Bea dan Cukai pada khususnya. Berbagai upaya telah dilakukan oleh Pusdiklat Bea dan Cukai untuk membangun dan meningkatkan komitmen organisasi para pegawainya.

Namun dalam kenyataannya masih terdapat pegawai Pusdiklat Bea dan Cukai yang kurang berkomitmen terhadap organisasi. Terdapat beberapa faktor yang mempengaruhi komitmen organisasi pegawai. Faktor-faktor tersebut antara lain adalah

\footnotetext{
${ }^{1}$ Widyaiswara di Pusdiklat Bea dan Cukai
} 
komunikasi interpersonal dan stres kerja. Kurangnya komunikasi interpersonal antar pegawai dalam menjalankan tugas dapat menurunkan komitmen organisasi pegawai. Begitu juga dengan stres kerja, semakin tinggi stres kerja pegawai dalam menjalankan tugas akan berakibat menurunnya komitmen organisasi pegawai.

Berdasarkan realita di atas, dalam upaya pencapaian tujuan organisasi, pegawai dituntut untuk memiliki komitmen organisasi yang tinggi. Hal ini dapat diwujudkan dengan memperhatikan dua faktor utama yang telah disebutkan, yaitu komunikasi interpersonal dan stres kerja.

Penelitian ini menguji dan menganalisis pengaruh langsung komunikasi interpersonal dan stres kerja terhadap komitmen organisasi, dengan subjek penelitian adalah pegawai Pusdiklat Bea dan Cukai.

\section{Komitmen Organisasi}

John R. Schermerhorn (2010:335) mendefinisikan," organizational commitment is the loyality of an individual to the organization. Individuals with a high organizational commitment identify strongly with the organization and take pride in considering themselves a member." Definisi ini mengandung makna bahwa komitmen organisasi sebagai kesetiaan seseorang terhadap organisasi. Seseorang yang memiliki komitmen organisasi yang tinggi akan mengikatkan secara kuat dengan organisasi dan bangga ketika memutuskan untuk menjadi anggota organisasi.

Menurut Robbins and Judge (2011:111), "organizational commitment is the degree to which an employee identifies with a particular organization and its goals and wishes to maintain membership in the organization". Komitmen organisasi adalah sejauh mana seorang pegawai mengikatkan dirinya ke organisasi tertentu dan tujuan organisasi, serta berharap untuk mempertahankan keanggotaan dalam organisasi tersebut.

Sedangkan Meyer dan Allen yang dikutip oleh Colquitt, LePine, dan Wesson (2011:69) menyatakan bahwa, "organizational commitment is defined as the desire on the part of an employee to remain a member of the organization". Komitmen organisasi adalah keinginan karyawan untuk tetap menjadi anggota organisasi.

Mowday seperti yang dikutip oleh Luthans (2011:147) mengatakan bahwa ,"as an attitude, organizational commitment is most often defined as (1) a strong desire to remain a member of a particular organization (2) a willingness to exert high levels of effort on behalf of the organization; and (3) a definite belief in, and acceptance of, the values and goals of the organization." Komitmen organisasi sering diartikan sebagai (1) keinginan yang kuat untuk tetap sebagai anggota organisasi tertentu (2) keinginan untuk berusaha keras sesuai kepentingan organisasi (3) kepercayaan dan penerimaan terhadap nilai dan tujuan organisasi. Dengan kata lain, komitmen organisasi merupakan refleksi loyalitas karyawan atau pegawai pada organisasi dan merupakan proses dimana anggota organisasi mengekspresikan perhatiannya pada organisasi dan keberhasilannya serta kemajuan yang berkelanjutan.

Ivancevich, Konopaske dan Matteson juga mengutip pendapat Moore (2008:184)," commitment to an organization involves three attitudes: (1) a sense of identification with the organization's goals, (2) a feeling of involment in organizational duties, and (3) a feeling of loyalty to the organization". Komitmen organisasi meliputi tiga sikap yaitu perasaan keterikatan terhadap tujuan organisasi. perasaan terlibat dalam kegiatan organisasi dan perasaan patuh terhadap organisasi.

Ada 3 tipe komitmen organisasi menurut J.P. Meyyer dan N.J. Allen yang dikutip oleh Colquitt, LePine dan Wesson (2011:71) sebagai berikut "these sorts of emotional 
reasons create Affective commitment, defined as a desire remain a member of an organization due to an emotional attachment to, and involvement with, that organization. Continued commitment, defined as a desire to remain a member of an organization because of awareness of the costs associated with leaving it. Normative commitment defined as a desire to remain a member of an organization due to a feeling of obligation."Komitmen afektif diartikan sebagai sebuah keinginan untuk tetap bertahan sebagai anggota organisasi karena adanya keterikatan secara emosional dan keterlibatan dengan organisasi. Seorang pegawai tetap menjadi anggota organisasi karena keinginannya. Sedangkan komitmen berkelanjutan diartikan sebagai keinginan untuk bertahan sebagai anggota organisasi karena kepeduliannya terhadap kerugian yang muncul jika dia meninggalkan organisasi. Adapun Komitmen normatif diartikan sebagai keinginan untuk tetap bertahan sebagai anggota organisasi karena dirasa sebagai suatu keharusan.

Berdasarkan deskripsi konsep di atas dapat disintesakan komitmen organisasi adalah keterikatan seseorang terhadap organisasi dengan indikator (1) keinginan seseorang untuk tetap menjadi anggota organisasi (2) kepercayaan terhadap nilai dan tujuan organisasi(3) penerimaan terhadap nilai dan tujuan organisasi (4) keterlibatan pada kegiatan organisasi (5) patuh pada organisasi.

\section{Komunikasi Interpersonal}

Devito (2007:5-6) menyatakan bahwa "interpersonal communication is the communication that takes place between two persons who have an established relationship; the people are in some way "connected". Komunikasi interpersonal adalah komunikasi yang terjadi antara dua orang yang telah memiliki hubungan, dimana orang - orang tersebut telah berhubungan dengan berbagai cara. Selanjutnya Devito mengatakan," often interpersonal communication takes place face to face: " . . . this is the type of interaction that probably comes to mind when you think of conversation. Because of technological advances, however, much conversation now takes place on line. The four major onl.ine types of conversation-e-mail, the mailing list group, instant messaging, and that chat group-differ from one another and from face to face interaction in important way." Biasanya komunikasi interpersonal itu dilakukan secara berhadap-hadapan atau bertatap muka langsung. Bentuk bertatap muka langsung sering kita sebut perbincangan atau percakapan. Karena kemajuan teknologi, percakapan itu sering dalam bentuk on line. Empat besar bentuk percakapan on line tersebut adalah e-mail, the mailing list group, instan messaging, atau dalam bentuk chat group.

Menurut Ivancevich, Konopaske dan Matteson (2008:361), “interpersonal communication is communication that flows individual to individual in face to face and group setting". Komunikasi interpersonal adalah komunikasi antara dua orang secara tatap muka dan dalam kelompok.

Menurut Slocum/Hellriegel (2009:249), pengertian komunikasi interpersonal adalah sebagai berikut,"an interpersonal communication network is the pattern of communication flows, relationships and understanding developed over time among people, rather than focusing on the individual and wether a specific message is received as intended by the sender.Komunikasi interpersonal adalah pola arus komunikasi, hubungan dan pemahaman yang telah dikembangkan diantara orang-orang, dan lebih berfokus pada kekhususan yang bersifat pribadi dari pesan yang diterima sesuai dengan maksud pengirim.

Sedangkan menurut Robbins and Judge (2011:380) mengatakan bahwa "interpersonal communication is how do group members transfer meaning between and among 
each other? They essentially rely on oral, written, and nonverbal communication". Komunikasi interpersonal adalah bagaimana anggota kelompok mengirim pesan antara dua orang atau antara satu dan lainnya. Mereka pada dasarnya berkomunikasi dengan bahasa lesan, tertulis dan bahasa non verbal.

Menurut Stephen P. Robbins dan Mary Coulter (2013:433), “interpersonal communication is communication between two or more people". Komunikasi interpersonal adalah komunikasi antara dua orang atau lebih.

Berdasarkan deskripsi konsep di atas dapat disintesakan komunikasi interpersonal adalah penyampaian dan penerimaan pesan antara dua orang secara tatap muka langsung atau melalui berbagai media dengan menggunakan bahasa verbal dan non verbal dengan indikator (1) penyampaian pesan antara dua orang secara berduaan saja atau dalam kelompok (2) penerimaan pesan antara dua orang secara berduaan saja atau dalam kelompok.

\section{Stres Kerja}

Marc J.Scharbracq (2003:27) mengatakan," work stress is considered to be a response to a loss or lack of control over our work performance. This leads to the following definition: stress evolves when we must do something that we are not/or willing to do. Stres kerja sebagai sebuah respon terhadap hilangnya kendali terhadap kinerja kita. Selanjutnya stres kerja diartikan sebagai tekanan yang terjadi ketika kita harus mengerjakan sesuatu yang tidak ingin kita kerjakan.

S. Sauter et. al.seperti yang dikutip Rae Andre (2008:153) berpendapat bahwa "job stress is the harmful physical and emotional responses that ocure when the requirements of the job do not match a worker's capabilities, resources or needs". Stres kerja adalah respon fisik dan emosional yang berbahaya yang terjadi ketika persyaratan pekerjaan tidak sesuai kemampuan pekerja, sumber daya, atau kebutuhan.

Menurut Slocum/Hellriegel (2009:188), mengatakan bahwa "job stress is a common and costly problem in the workplace, leaving few workers unthouced". Stres kerja adalah suatu masalah umum dan mahal di tempat kerja meninggalkan beberapa pekerja tak tersentuh.

Menurut Richard L. Daft (2010:461) mengatakan bahwa " most people have a general idea of what a stressful job is like: difficult, uncomfortable, exhausting, even frightening". Kebanyakan orang memiliki ide umum mengenai apa itu stres kerja adalah seperti kesulitan, ketidaknyamanan, melelahkan dan bahkan menakutkan.

Menurut Ivancevich dan Matteson seperti yang dikutip oleh Luthans (2011:279), mengatakan bahwa,"although there are numerous definitions and much debate about the meaning of job stresss, Ivancevich and Matteson define stresss simply as "the interaction of the individual with the environment," but then they go on the give a more detailed working definition, as follows:"an adaptive respons, mediated by individual differences and / or psychological process, that is qonsequence of any external (environmental) action, situation, or even that places excessive psychological and/or physical demands on a person". Meskipun ada banyak pengertian dan perdebatan tentang arti dari stres kerja, stres secara sederhana didefinisikan sebagai interaksi antara individu dengan lingkungan. Kemudian secara lebih detil stres diartikan dalam pengertian pekerjaan, sebagai sebuah respon adaptif yang dimediasi oleh perbedaan individu dan atau proses psikologi, sebagai akibat dari aksi lingkungan, situasi atau peristiwa yang menyebabkan tuntutan fisik dan atau psikologi secara berlebihan terhadap seseorang. 
Selanjutnya Beehr and Newman (2011:227) mendefinisikan,"job stress as a condition arising from the interaction of people and their jobs and characterized by changes within people that force them to deviate from their normal functioning." Dalam pengertian yang lain, stres kerja diartikan sebagai sebuah kondisi yang terjadi sebagai hasil interaksi antara pegawai dengan pekerjaan mereka dan dikarakteristikan atau ditandai oleh perubahan manusia yang memaksa mereka untuk menyimpang dari fungsi normal mereka.

Berdasarkan deskripsi konsep di atas dapat disintesakan stres kerja adalah respon adaptif seseorang terhadap tuntutan fisik dan atau psikologi terhadapnya sebagai akibat dari interaksinya dengan pekerjaan dan lingkungan kerjanya dengan indikator (1) tekanan (2) kesulitan (3) ketidaknyamanan (4) kelelahan (5) ketakutan.

\section{METODE}

Penelitian ini dilaksanakan pada Pusdiklat Bea dan Cukai. Populasi terjangkau dalam penelitian ini berjumlah 56 orang pegawai pelaksana. Sampel diambil dengan menggunakan teknik simple random sampling dengan jumlah 50 orang pegawai pelaksana.

Penelitian ini menggunakan metode penelitian survey dengan menggunakan analisis jalur (path analysis) untuk mengetahui adanya pengaruh antar variabel sesuai dengan model kausal yang terbentuk. Sebelum kuesioner digunakan dalam penelitian ini, terlebih dahulu dilakukan ujicoba untuk menentukan validitas dan reabilitas instrumen. Hasil tersebut digunakan sebagai instrumen untuk mengambil data dalam penelitian di lapangan. Analisis data meliputi: 1) deskripsi data; 2) uji prasyarat analisis normalitas; 3) analisis jalur yang meliputi: analisis model regresi, pengujian hipotesis dan penentuan tingkat pengaruh.

\section{HASIL DAN PEMBAHASAN}

\section{Pengaruh Langsung Komunikasi Interpersonal Terhadap Komitmen Organisasi}

Berdasarkan hasil perhitungan koefisien jalur sebesar 0,364 dan nilai koefisien korelasi sebesar 0,493. Dengan demikian terdapat pengaruh langsung positif komunikasi interpersonal terhadap komitmen organisasi.

Hasil penelitian tersebut sesuai dengan teori yang menunjukkan pengaruh komunikasi interpersonal terhadap komitmen organisasi menurut J.M. Putti S, Aryee and J. Phua seperti yang dikutip oleh Ivancevich, Konopaske, Matteson (2008:361) mengemukakan sebagai berikut, "in addition to providing needed information, interpersonal communication also influences how people feel about the organization. For axample, research indicates thas satisfaction with communication relationships affects organizational commitment. Dalam rangka menyediakan informasi yang diperlukan, komunikasi interpersonal berpengaruh terhadap perasaan orang terhadap organisasi. Sebagai contoh, penelitian menunjukkan bahwa kepuasan berkomunikasi berpengaruh terhadap komitmen organisasi.

Selain itu Gery Dessler seperti yang dikutip oleh Sopiah (2008:159) mengatakan bahwa ada sejumlah cara yang biasa dilakukan untuk membangun komitmen organisasi yaitu "make it charismatic, build the tradition, have comprehensive grievance procedures, provide extensive two way communications, create a sense of community". Untuk membangun komitmen organisasi cara yang dilakukan adalah dengan membangun karisma, membuat suatu aturan yang menjadi kebiasaan, diperlukan komunikasi dua arah yang 
lebih luas. Robbins and Judge (2011:111), "organizational commitment is the degree to which an employee identifies with a particular organization and its goals and wishes to maintain membership in the organization". Komitmen organisasi adalah sejauh mana seorang pegawai mengikatkan dirinya ke organisasi tertentu dan tujuan organisasi, serta berharap untuk mempertahankan keanggotaan dalam organisasi tersebut.

Sedangkan Meyer dan Allen yang dikutip oleh Colquitt, LePine, dan Wesson (2011:69) menyatakan bahwa, "organizational commitment is defined as the desire on the part of an employee to remain a member of the organization". Komitmen organisasi adalah keinginan karyawan untuk tetap menjadi anggota organisasi. Mowday seperti yang dikutip oleh Luthans (2011:147) mengatakan bahwa "'as an attitude, organizational commitment is most often defined as (1) a strong desire to remain a member of a particular organization (2) a willingness to exert high levels of effort on behalf of the organization; and (3) a definite belief in, and acceptance of, the values and goals of the organization." Komitmen organisasi sering diartikan sebagai (1) keinginan yang kuat untuk tetap sebagai anggota organisasi tertentu (2) keinginan untuk berusaha keras sesuai kepentingan organisasi (3) kepercayaan dan penerimaan terhadap nilai dan tujuan organisasi. Dengan kata lain, komitmen organisasi merupakan refleksi loyalitas karyawan atau pegawai pada organisasi dan merupakan proses dimana anggota organisasi mengekspresikan perhatiannya pada organisasi dan keberhasilannya serta kemajuan yang berkelanjutan.

Hal ini mencerminkan ketepatan komunikasi interpersonal menyebabkan tingginya komitmen organisasi.

\section{Pengaruh Langsung Stres Kerja Terhadap Komitmen Organisasi}

Berdasarkan hasil perhitungan koefisien jalur sebesar -0,309 dan nilai koefisien korelasi sebesar -0,461. Dengan demikian terdapat pengaruh langsung negatif stres kerja terhadap komitmen organisasi.

Hasil penelitian tersebut sesuai dengan teori yang menunjukkan pengaruh stres kerja terhadap komitmen organisasi menurut Bedeian mengatakan seperti yang dikutip oleh Colquitt, LePine dan Wesson (2011:159) bahwa, "hindrance stressors avoke strains, which are generally dissatisfying to people, satisfaction has a strong impact on the degree to which people feel commited to their organization". Hindran stresor akan menghasilkan strain yang tidak memuaskan seseorang. Sedangkan kepuasan seseorang memiliki pengaruh kuat terhadap komitmen seseorang terhadap organisasi. Hal tersebut dipetakan pada gambar berikut ini yang menunjukkan pengaruh hindran stresor terhadap komitmen organisasi.

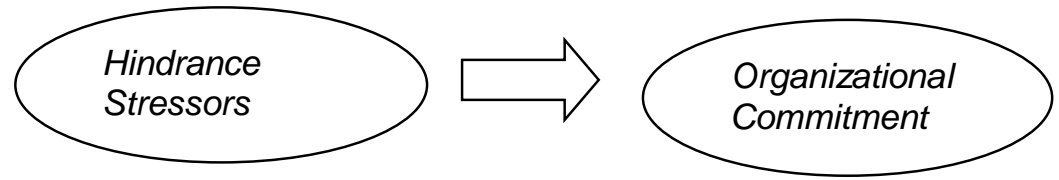

Gambar 2.6 Effects of Hindrance Stressors on Commitment.

Sources: J.A. LePine, N.P. Podsakoff,and M.A. LePine," A Meta-Analytic Test of the Challenge Strssor-Hindrance Stressor Framework: An Explanation for Inconsistent for Inconsistent for Inconsistent Relationships Among Stressors

Performance," Acadedemy of Management Journal 48(2005).pp.764-75

Selanjutnya Colquitt, LePine dan Wesson (2011:159) mengatakan,"hindrance stressors have a strong negative relationship with organizational commitment. People who experience higher levels of hindrance stressors tend to have lower levels of affective commitment 
and normative commitment. Relationships with Continuance Commitment are weaker. Hindran stresor memiliki pengaruh negatif yang kuat terhadap komitmen organisasi. Orang yang mengalami hindran stresor yang tinggi akan cenderung untuk memiliki tingkat komitmen organisasi afektif dan komitmen organisasi normatif yang rendah. Sedangkan hindran stresor memiliki pengaruh yang lemah terhadap komitmen organisasi berkelanjutan.

A. Khatabi, H. Asadi dan M. Hamidi (2013) mengatakan"the results indicated a significant and negative relationship between job stress and organizational commitment. As the employee's job stress increases, their commitment to organization decreases and vice versa." Terdapat pengaruh negatif yang signifikan antara stres kerja dan komitmen organisasi. Ketika stres kerja pegawai naik maka komitmen pegawai terhadap organisasinya menurun. Slocum/Hellriegel (2009:188), mengatakan bahwa "job stress is a common and costly problem in the workplace, leaving few workers unthouced". Stres kerja adalah suatu masalah umum dan mahal di tempat kerja meninggalkan beberapa pekerja tak tersentuh. Sdangkan Richard L. Daft (2010:461) mengatakan bahwa "most people have a general idea of what a stressful job is like: difficult, uncomfortable, exhausting, even frightening". Kebanyakan orang memiliki ide umum mengenai apa itu stres kerja adalah seperti kesulitan, ketidaknyamanan, melelahkan dan bahkan menakutkan. Ivancevich dan Matteson seperti yang dikutip oleh Luthans (2011:279), mengatakan bahwa ,"although there are numerous definitions and much debate about the meaning of job stresss, Ivancevich and Matteson define stresss simply as "the interaction of the individual with the environment," but then they go on the give a more detailed working definition, as follows:"an adaptive respons, mediated by individual differences and/or psychological process, that is qonsequence of any external (environmental) action, situation, or even that places excessive psychological and/or physical demands on a person". Stres kerja didefinisikan sebagai interaksi antara individu dengan lingkungan. Kemudian secara lebih detil stres diartikan dalam pengertian pekerjaan, sebagai sebuah respon adaptif yang dimediasi oleh perbedaan individu dan atau proses psikologi, sebagai akibat dari aksi lingkungan, situasi atau peristiwa yang menyebabkan tuntutan fisik dan atau psikologi secara berlebihan terhadap seseorang.

Hal ini mencerminkan tingginya stres kerja menyebabkan rendahnya komitmen organisasi.

\section{Pengaruh Langsung Komunikasi Interpersonal Terhadap Stres Kerja}

Berdasarkan hasil perhitungan koefisien jalur sebesar -0,418 dan nilai koefisien korelasi sebesar -0,418. Dengan demikian terdapat pengaruh langsung negatif komunikasi interperonal terhadap stres kerja.

Hasil penelitian tersebut sesuai dengan teori yang menunjukkan pengaruh komunikasi interpersonal terhadap stres kerja menurut J.R. Carlson and R.W. Zmud seperti yang dikutip oleh Ivancevich, Konopaske dan Matteson (2008:355), mengatakan bahwa " the absence of job-related information can create unnecessary stress among organization members". Tidak adanya informasi yang terkait pekerjaan cukup dapat menciptakan konflik dan stres di antara anggota organisasi.

Luthans (2011:300) mengatakan," it logically follows that each of these areas would be the focus of attention in developing organizational coping strategies. In the other words, each of the specific stressors would be worked on in order to eliminate or reduce job stress. For example, in the policy area, attention would be given to making performance reviews and pay plans as equitable and as fair as possible. In the structural area, steps would be taken to back away from high degrees of formalization and specialization. The same would be done in the areas of physical 
conditions (for example, communication and information sharing would be improved, and ambiguous or conflicting goals would be clarified or resolved)". Secara logis bahwa setiap bidang ini akan menjadi fokus perhatian dalam mengembangkan strategi organisasi. Dengan kata lain, masing-masing dari penyebab stres tertentu akan bekerja untuk menghilangkan atau mengurangi stres kerja. Misalnya dalam bidang kebijakan, langkah-langkah akan diambil untuk mengurangi derajat formalisasi dan spesialisasi. Hal yang sama akan dilakukan di bidang kondisi fisik (misalnya, komunikasi dan berbagi informasi akan ditingkatkan, dan ambigu atau hal-hal yang bertentangan akan diklarifikasi atau diselesaikan). Dari uraian di atas dapat diketahui bahwa komunikasi dan berbagi informasi (komunikasi interpersonal) ditingkatkan sebagai salah satu strategi untuk mengurangi stres kerja. Ivancevich, Konopaske dan Matteson (2008:361) menjelaskan "interpersonal communication is communication that flows individual to individual in face to face and group setting". Komunikasi interpersonal adalah komunikasi antara dua orang secara tatap muka dan dalam kelompok. Sedangkan Slocum/Hellriegel (2009:249), menjelaskan," an interpersonal communication network is the pattern of communication flows, relationships and understanding developed over time among people, rather than focusing on the individual and wether a specific message is received as intended by the sender". Komunikasi interpersonal adalah pola arus komunikasi, hubungan dan pemahaman yang telah dikembangkan diantara orang-orang, dan lebih berfokus pada kekhususan yang bersifat pribadi dari pesan yang diterima sesuai dengan maksud pengirim. Robbins and Judge (2011:380) mengatakan bahwa "interpersonal communication is how do group members transfer meaning between and among each other? They essentially rely on oral, written, and nonverbal communication". Komunikasi interpersonal adalah bagaimana anggota kelompok mengirim pesan antara dua orang atau antara satu dan lainnya. Mereka pada dasarnya berkomunikasi dengan bahasa lesan, tertulis dan bahasa non verbal.

Hal ini mencerminkan ketepatan komunikasi interpersonal menyebabkan rendahnya stres kerja.

\section{PENUTUP}

Kesimpulan. Berdasarkan hasil penelitian ini dapat disimpulkan bahwa: (1) Terdapat pengaruh positif komunikasi interpersonal terhadap komitmen organisasi yang ditentukan oleh derajat besarnya pengaruh dalam bentuk koefisien korelasi dan koefisien jalur. Nilai koefisien jalur menentukan besaran varians komitmen organisasi ditentukan oleh komunikasi interpersonal. Selanjutnya dapat diketahui signifikansi pengaruh antara komunikasi interpersonal terhadap komitmen organisasi secara parsial. Hal ini memiliki makna dan penegasan bahwa komunikasi interpersonal secara empiris bukan satu-satunya variabel prediktor bagi varians skor komitmen organisasi. (2) Terdapat pengaruh negatif stres kerja terhadap komitmen organisasi yang ditentukan oleh derajat besarnya pengaruh dalam bentuk koefisien korelasi dan koefisien jalur. Nilai koefisien jalur menentukan besaran varians komitmen organisasi ditentukan oleh stres kerja. Selanjutnya dapat diketahui signifikansi pengaruh antara stres kerja terhadap komitmen organisasi secara parsial. Hal ini memiliki makna dan penegasan bahwa stres kerja secara empiris bukan satu-satunya variabel prediktor bagi varians skor komitmen organisasi. (3) Terdapat pengaruh negatif komunikasi interpersonal terhadap stres kerja yang ditentukan oleh derajat besarnya pengaruh dalam bentuk koefisien korelasi dan koefisien jalur. Nilai koefisien jalur menentukan besaran varians stres kerja ditentukan oleh komunikasi interpersonal. Selanjutnya dapat 
diketahui signifikansi pengaruh antara komunikasi interpersonal terhadap stres kerja secara parsial. Hal ini memiliki makna dan penegasan bahwa komunikasi interpersonal secara empiris bukan satu-satunya variabel prediktor bagi varians skor stres kerja.

Saran. Beberapa hal yang disarankan dalam penellitian ini adalah sebagai berikut: (1) Bagi organisasi agar lebih memperhatikan kebutuhan pegawai, baik menyangkut kebutuhan untuk dapat berkomunikasi interpersonal secara tepat dan kebutuhan untuk mengelola stres kerja, bagi kepentingan organisasi. (2) Bagi pegawai, agar dapat mengembangkan kompetensi dan wawasan, terutama yang berkaitan cara melakukan komunikasi interpersonal secara tepat dan mengelola stres kerja, sehingga komitmen organisasi pegawai semakin meningkat. (3) Bagi peneliti lain, agar dapat dijadikan bahan rujukan dalam rangka penelitian lanjutan terkait dengan pengaruh komunikasi interpersonal dan stres kerja terhadap komitmen organisasi. 


\section{DAFTAR RUJUKAN}

Andre, Rae. Organizational Behavior Pearson International Edition. New Jersey: Pearson Prentice Hall, 2008.

Colquitt, Lepine, Wesson. Organizational Behavior: Improving Performance and Commitment In The Workplace Second Edition. New York: The McGraw-Hill Companies Inc., 2011.

Daft, Richard L. New Era of Management Ninth Edition. South-Western: Cengage Learning, 2010.

Devito, Joseph A. The Interpersonal Communication Book Eleventh Edition. USA: Pearson Education Inc., 2007.

Ivancevich, Konopaske, Matteson. Organizational Behavior and Management Eight Edition. New York: Mc Graw-Hill Companies Inc., 2008.

Journal of the Indian Academy of Applied Psychology, http//medind.nic.in/jak/t08/i2/jakt08i2p267.pdf (diakses 15 Juni 2013).

Luthans, Fred. Organizational Behavior Twelfth Edition. New York: The Mc Graw Hill Companies Inc., 2011.

Robbins, Stephen P., dan Timothi A. Judge. Organizational Behavior Fourteenth Edition. New Jersey: Pearson Education Inc., 2011.

Robbins, Stephen P., Marry Coulter. Management Eleventh Edition. England: Pearson Horizon, 2013.

Schabracq, M. J., J. A. M. Winnubst, and C.L. Cooper. The Handbook of Work and Health Psychology. Belanda: John Wiley \& Sons Ltd, 2003.

Shermerhorn, John R. Introduction to Management 10 th Edition. Asia: John Wiley \& Sons Inc., 2010.

Slocum, Herriegel. Principles of Organizational Behavior Twelfth Edition. Canada: South Western, 2009.

Sopiah, Perilaku Organisasional. Jakarta: C.V. Andi Offset, 2008. 